\title{
Knowledge and practices related to dengue and its vector: a community-based study from Southeast Brazil
}

\author{
Adorama Candido Alves ${ }^{[1]}$, Amaury Lelis dal Fabbro ${ }^{[1]}$, Afonso Dinis Costa Passos ${ }^{[1]}$, \\ Ariadne Fernanda Tesarin Mendes Carneiro ${ }^{[2]}$, Tatiane Martins Jorge ${ }^{[2]}$ \\ and Edson Zangiacomi Martinez ${ }^{[1]}$
}

[1] Departamento de Medicina Social, Faculdade de Medicina de Ribeirão Preto, Universidade de São Paulo, Ribeirão Preto, São Paulo, Brasil. [2] Divisão de Fonoaudiologia, Departamento de Oftalmologia, Otorrinolaringologia e Cirurgia da Cabeça e Pescoço, Universidade de São Paulo, Ribeirão Preto, São Paulo, Brasil.

\begin{abstract}
Introduction: This study investigated the knowledge of users of primary healthcare services living in Ribeirão Preto, Brazil, about dengue and its vector. Methods: A cross-sectional survey of 605 people was conducted following a major dengue outbreak in 2013. Results: Participants with higher levels of education were more likely to identify correctly the vector of the disease. Conclusions: The results emphasize the relevance of health education programs, the continuous promotion of educational campaigns in the media, the role of the television as a source of information, and the importance of motivating the population to control the vector.
\end{abstract}

Keywords: Knowledge. Attitude. Dengue vector.

Vector control, the most important strategy to prevent and control dengue, requires the cooperation of entire communities, as it is not solely a government responsibility. Communities should be educated about eliminating the potential for breeding and other prevention strategies, which requires an understanding of their knowledge and practices concerning dengue. There is a gap between knowledge and attitudes about dengue in various Brazilian regions ${ }^{(1)(2)}$. Thus, this cross-sectional study investigated the knowledge of adults who are users of primary healthcare services of Ribeirão Preto, in Southeast Brazil, about dengue and its vector (transmission, symptoms, prevention, and treatment), and their source of the information and health practices.

The municipality of Ribeirão Preto, is divided into five health districts, consisting of 41 primary healthcare units with diverse demographic characteristics ${ }^{(3)}$. For sampling purposes, the healthcare units were classified using the São Paulo Social Vulnerability Index [Índice Paulista de Vulnerabilidade Social (IPVS)], based on their predominant areas of coverage. The IPVS, proposed by the State Data Analysis System Foundation, classifies geographical areas into six categories of social vulnerability. Thus, the units were grouped by health district and IPVS classification to form 10 strata. One unit was randomly selected from each stratum for the interviews. The minimum

Corresponding author: Prof. Edson Zangiacomi Martinez.

e-mail: edson@fmrp.usp.br

Received 14 July 2015

Accepted 23 September 2015 sample size of 605 individuals was determined using a stratified sampling design, a confidence coefficient of 0.95 , and an absolute precision of 0.04 for the proportion of individuals with satisfactory knowledge about dengue control. In 2008, $52 \%$ of the municipality's urban population had exclusive use of the public healthcare resources and $80 \%$ used these services at some time ${ }^{(3)}$. Thus, this study's sample of 605 participants is considered representative of the municipality's population.

Individuals were invited to participate in the study while they waited for medical care in the health units. A poster created using colorful images obtained from the Internet of the Aedes aegypti mosquito and seven other insects (Rodnius prolixus, Angarotipula sp., Anopheles gambiae, Palexorista sp., Polistes metricus, Tabanus sp., and Culex sp.), was used to assess participants' ability to identify the dengue vector. Aedes albopictus, first reported in São Paulo State in September $1986^{(4)}$, was not included because its vector competence for dengue viruses in Brazil remains uncertain ${ }^{(5)}$.

Data were collected from July 2013 to September 2014, following a major dengue outbreak. All data were collected before the first autochthonous transmission of the chikungunya virus in Brazil that was detected in September 2014(6). Thus, there was no possibility of confusion between the two different diseases. The proportions of respondents who correctly identified the dengue vector were analyzed using the general linear model and SAS software version 9.3.

The respondents' characteristics are presented in Table 1. The disproportionate number of women in the study was consistent with gender differences in the use of primary healthcare services in $\mathrm{Brazil}^{(7)}$. The percentage of respondents claiming to have dengue previously (26.9\%) is imprecise because 
TABLE 1 - Participants' demographic characteristics and their knowledge and attitudes about dengue.

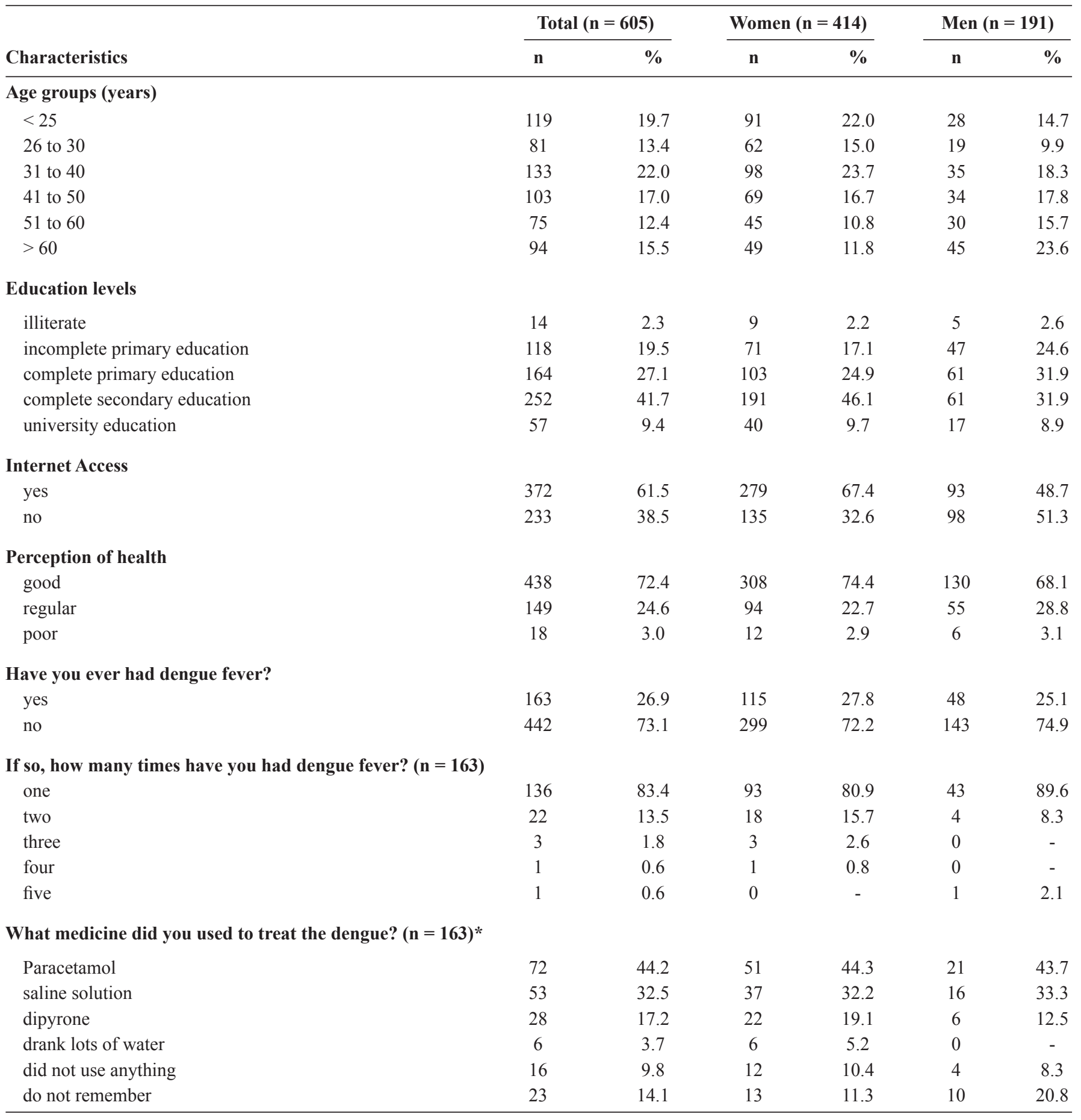

*Respondents were allowed to choose more than one answer.

dengue may easily be confused with other causes of fever, its clinical manifestations are not always present ${ }^{(8)}$, and not all suspected cases are laboratory confirmed during epidemics ${ }^{(9)}$. Most of the respondents did not correctly identify the time of day that mosquitos bite (Table 2). More than half reported that mosquitoes bite at any time. This belief is not entirely wrong because although their activity is predominantly diurnal ${ }^{(10)}$, mosquitoes bite at any time if there is enough ambient light.
However, accurate knowledge of the Aedes' biting habits is important, as mosquito repellents will be ineffective if used at night. Among the 11 respondents who believed that dengue is transmitted through standing water, three completed secondary education, five completed primary education, and three had not completed primary education. A large number of respondents did not know the number of times a person could have dengue fever; only $3.5 \%$ responded that it was four times. 
TABLE 2 - Participants' knowledge of dengue and their perceptions of the risk of becoming infected with dengue.

\begin{tabular}{|c|c|c|c|c|c|c|}
\hline \multirow[b]{2}{*}{ Knowledge and perceptions } & \multicolumn{2}{|c|}{ Total $(n=605)$} & \multicolumn{2}{|c|}{ Women $(n=414)$} & \multicolumn{2}{|c|}{ Men $(n=191)$} \\
\hline & $\mathbf{n}$ & $\%$ & $\mathbf{n}$ & $\%$ & $\mathbf{n}$ & $\%$ \\
\hline \multicolumn{7}{|c|}{ Perception of risk of dengue infection } \\
\hline very high & 84 & 13.9 & 57 & 13.8 & 27 & 14.1 \\
\hline high & 216 & 35.7 & 144 & 34.8 & 72 & 37.7 \\
\hline medium & 180 & 29.8 & 130 & 31.4 & 50 & 26.2 \\
\hline low & 66 & 10.9 & 45 & 10.9 & 21 & 11.0 \\
\hline very low & 17 & 2.8 & 10 & 2.4 & 7 & 3.7 \\
\hline do not know & 42 & 6.9 & 28 & 6.7 & 14 & 7.3 \\
\hline
\end{tabular}

How serious is the dengue infection?
very serious
more or less serious
it is not serious
do not know

How is dengue fever transmitted?

\author{
through a mosquito \\ through standing water \\ do not know
}

What time of year do most cases of dengue occur?

rainy periods

at any time of the year

during periods without rain

do not know

How many times can a person have dengue?

only once

two times

up to three times

up to four times

there is no limit to the number of times

do not know

$\begin{array}{ccc}524 & 86.6 & 367 \\ 72 & 11.9 \\ 4 & 0.7 \\ 5 & 0.8\end{array}$

367
44
2
1

88.7
10.6
0.5
0.2

157

82.2

14.7

1.0

2.1

$\begin{array}{ll}2 & 2.1\end{array}$

592

11

2

97.9
1.8
0.3

407
6
1

98.3
1.4
0.2

185

96.9

2.6

0.5

10.5

$\begin{array}{cccccc}371 & 61.3 & 248 & 59.9 & 123 & 64.4 \\ 188 & 31.1 & 136 & 32.8 & 52 & 27.2 \\ 28 & 4.6 & 19 & 4.6 & 9 & 4.7 \\ 18 & 3.0 & 11 & 2.7 & 7 & 3.7\end{array}$

The mosquito that transmits dengue has the habit of biting people:

$$
\begin{aligned}
& \text { during the day } \\
& \text { during the night } \\
& \text { at any time }
\end{aligned}
$$

do not know

$\begin{array}{cc}23 & 3.8 \\ 110 & 18.2 \\ 123 & 20.3 \\ 21 & 3.5 \\ 155 & 25.6 \\ 173 & 28.6\end{array}$

18
74
78
16
115
113

$\begin{array}{ccc}4.3 & 5 & 2.6 \\ 17.9 & 36 & 18.8 \\ 18.8 & 45 & 23.6 \\ 3.9 & 5 & 2.6 \\ 27.8 & 40 & 20.9 \\ 27.3 & 60 & 31.4\end{array}$

\begin{tabular}{cccccc}
216 & 35.7 & 153 & 37.0 & 63 & 33.0 \\
36 & 5.9 & 29 & 7.0 & 7 & 3.6 \\
321 & 53.1 & 212 & 51.2 & 109 & 57.1 \\
32 & 5.3 & 20 & 4.8 & 12 & 6.3 \\
\hline
\end{tabular}

Television was the main source of information about dengue $(87.8 \%)$, followed by pamphlets/posters $(41.8 \%)$, internet $(17.5 \%)$, hospitals and health units $(17.4 \%)$, radio (12.2\%), newspapers $(9.7 \%)$, children's schools $(5.6 \%)$, friends $(4.6 \%)$, relatives $(4.3 \%)$, schools, colleges, or faculty $(4 \%)$, and church or religious groups $(2.2 \%)$. The percentage of respondents who cited the internet as an information source ranged from $0 \%$ (illiterate) to $45.6 \%$ (university-educated). During data collection, several of the educational pamphlets/ posters in the health units were found to represent the mosquito in a very stylized and often humanized form, with wicked facial expressions, similar to cartoon characters, as if dengue transmission is a rational act. Exposure to these metaphors could have adversely affected respondents' ability to identify realistic pictures of the vector and their understanding of the dynamics of disease transmission.

When asked to list dengue symptoms, most (79.7\%) participants listed fever, which is similar to other studies ${ }^{(11)(12)(13)}$. This result was probably due to educational messages in the mass media, citing fever as dengue's primary symptom ${ }^{(11)}$. The recognition of dengue symptoms is crucial for early treatment ${ }^{(13)}$. Other symptoms reported by participants in descending order 
TABLE 3 - Characteristics of the respondents who correctly identified the dengue vector.

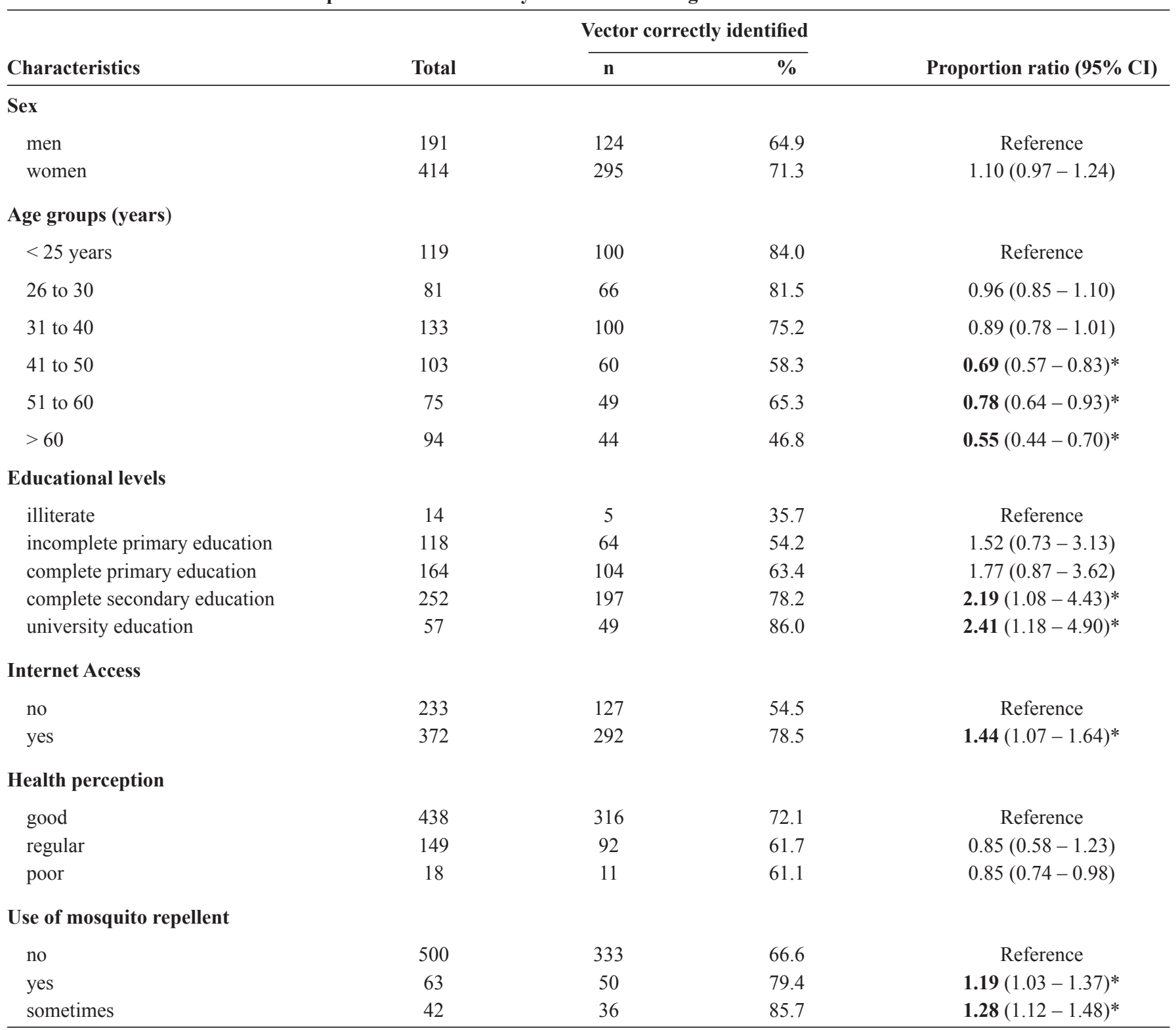

95\% CI: confidence interval; CI that does not include the value 1 are marked with an asterisk and they indicate significant differences at 0.05 level.

of frequency were muscular pain $(66.6 \%)$, headache $(65.1 \%)$, redness of the skin (36\%), pain behind the eyes (26.1\%), fatigue (20.8\%), joint pain (17.4\%), vomiting (16.2\%), diarrhea (15\%), malaise $(5.8 \%)$, itch $(5.1 \%)$, nausea $(4.5 \%)$, loss of appetite (4.3\%), dizziness $(1.5 \%)$, and weakness $(1.2 \%)$.

Only $10.4 \%$ of respondents used mosquito repellent regularly; fewer used homemade repellents (e.g., citronella oil and alcohol with Indian clove). The proportion of respondents who used repellent regularly showed a gradual increase with educational level, ranging from $7.1 \%$ among the illiterate respondents to $21.1 \%$ among the respondents with a university education.

Participants' answers to an open-ended question about ways to prevent dengue revealed that only $8.8 \%$ believed that avoiding dengue was impossible or did not know how to avoid it. Other methods included not allowing standing water to accumulate $(67.4 \%)$, maintaining hygiene and cleanliness in the environment $(21.3 \%)$, preventing mosquito proliferation (9.4\%), increasing public awareness and knowledge (8.1\%), not leaving potential breeding environments exposed (tires, buckets, water tanks, and water drains) (7.3\%), cooperating with local governments and health surveillance, encouraging public investments in sanitation services (3.5\%), and following the instructions of health surveillance or community-based health workers e.g., allowing home inspections $(0.7 \%)$.

In response to an open-ended question about what participants actually did to prevent dengue, $9.9 \%$ believed it was possible to avoid dengue, but did nothing to prevent it. The most frequent answers were avoiding the accumulation of standing water $(44.3 \%)$ and keeping the house and/or yard clean (23\%). 
When respondents were shown the poster to identify the insects responsible for dengue fever transmission, 3.5\% said they did not know. The remaining respondents identified more than one insect; $69.3 \%$ correctly identified Aedes aegypti, $12.1 \%$ indicated Angarotipula sp. (a cranefly), 8.3\% chose Culex sp., and $6.1 \%$ indicated Anopheles gambiae. Two respondents selected Rodnius prolixus, two chose the fly, Palexorista sp. and the wasp, Polistes metricus, while three respondents answered that none of the insects on the poster transmit dengue.

The correct identification of the dengue vector varied with respondents' age and education (Table 3). The proportion of correct identifications decreased from $84 \%$ among the respondents under 25 years of age to $46.8 \%$ among those above 60 years of age. Higher educational level and internet access increased the likelihood of identifying the vector, with a proportion ratio (PR) of 1.44 [95\% confidence interval $(95 \% \mathrm{CI})$ : 1.07-1.64] compared to those without internet access. This finding was still significant when the model was adjusted for age $(\mathrm{PR}=1.24,95 \% \mathrm{CI}: 1.07-1.44)$ or educational level $(\mathrm{PR}=1.27$, 95\% CI: 95\%: 1.10-1.47). The proportion of correct identifications of the vector was significantly higher among respondents who used mosquito repellent sometimes or regularly, and the results remained significant after adjusting for age or educational level.

This study's limitation is that the results cannot be generalized to a broader population. However, they are similar to those of other studies ${ }^{(1)(2)(11)(12)(13)}$, and they reinforce the relevance of health education programs, the continuous promotion of educational campaigns in the media, the role of television as a source of information, and the importance of motivating people to control the vector.

Recently, a phase 3 efficacy trial showed that a tetravalent dengue vaccine was efficacious against virologically confirmed dengue $^{(14)}$, which brings new hope for control of the disease. However, efforts must continue to improve mosquito control, given the likely rise of other arboviruses transmitted by Aedes mosquitoes, such as the Zika virus infection, identified the first time in Brazil in $2015^{(15)}$, and Chikungunya fever, first detected in Brazil in 2014(ต).

\section{CONFLICT OF INTEREST}

The authors declare that there is no conflict of interest.

\section{FINANCIAL SUPPORT}

This work has received financial support by National Counsel of Technological and Scientific Development [Conselho Nacional de Desenvolvimento Cientifico e Tecnológico (CNPq)] (Process 305942/2012-3).

\section{REFERENCES}

1. Chiaravalloti Neto F. Conhecimentos da população sobre dengue, seus vetores e medidas de controle em São José do Rio Preto, São Paulo. Cad Saude Publica 1997; 13:447-453.

2. Claro LBL, Tomassini HCB, Rosa MLG. Prevenção e controle do dengue: uma revisão de estudos sobre conhecimentos, crenças e práticas da população. Cad Saude Publica 2004; 20:1447-1457.

3. Prefeitura Municipal de Ribeirão Preto. Secretaria Municipal da Saúde, Departamento de Vigilância em Saúde. Fatores de risco relacionados à saúde da população residente na zona urbana de Ribeirão Preto (SP), 2008-2011. Ribeirão Preto, 2011. 128p.

4. Brito M, Marques GRAM, Marques CCA, Tubaki RM. Primeiro encontro de Aedes (Stegomyia) albopictus (Skuse) no Estado de São Paulo (Brasil). Rev Saude Publica 1986; 20:489.

5. Gratz NG. Critical review of the vector status of Aedes albopictus. Med Vet Entomol 2004; 18: 215-227.

6. Honório NA, Câmara DCP, Calvet GA, Brasil P. Chikungunya: an arbovirus infection in the process of establishment and expansion in Brazil. Cad Saude Publica 2015; 31:906-908.

7. Gomes R, Moreira MCN, Nascimento ED, Rebello LEFS, Couto MT, Schraiber LB. Men don't come! Absence and/or invisibility in primary healthcare services. Cien Saude Colet 2011; 16:983-992.

8. Bhatt S, Gething PW, Brady OJ, Messina JP, Farlow AW, Moyes $\mathrm{CL}$, et al. The global distribution and burden of dengue. Nature 2013; 496:504-507.

9. Santos KCD, Siqueira Júnior JB, Zara ALDSA, Barbosa JR, Oliveira ESFD. Avaliação dos atributos de aceitabilidade e estabilidade do sistema de vigilância da dengue no estado de Goiás, 2011. Epidemiol Serv Saude 2014; 23:249-258.

10. Natal D. Bioecologia do Aedes aegypti. Biológico 2002; 64: $205-$ 207.

11. Hairi F, Ong CH, Suhaimi A, Tsung TW, bin Anis Ahmad MA, Sundaraj C, et al. A knowledge, attitude and practices (KAP) study on dengue among selected rural communities in the Kuala Kangsar district. Asia Pac J Public Health 2003; 15:37-43.

12. Mayxay M, Cui W, Thammavong S, Khensakhou K, Vongxay $\mathrm{V}$, Inthasoum L, et al. Dengue in peri-urban Pak-Ngum district, Vientiane capital of Laos: a community survey on knowledge, attitudes and practices. BMC Public Health 2013; 13:434.

13. Nalongsack S, Yoshida Y, Morita S, Sosouphanh K, Sakamoto J. Knowledge, attitude and practice regarding dengue among people in Pakse, Laos. Nagoya J Med Sci 2009; 71:29-37.

14. Villar L, Dayan GH, Arredondo-García JL, Rivera DM, Cunha $\mathrm{R}$, Deseda $\mathrm{C}$, et al. Efficacy of a tetravalent dengue vaccine in children in Latin America. N Eng1 J Med 2015; 372:113-123.

15. Zanluca C, Melo VCAD, Mosimann ALP, Santos GIVD, Santos CNDD, Luz K. First report of autochthonous transmission of Zika virus in Brazil. Mem Inst Oswaldo Cruz 2015; 110:569-572. 